\title{
Sustainable Tourism as a Way of Improving Active Life
}

\author{
Elena G. Leontyeva ${ }^{a *}$, Francesc Romagosa ${ }^{b}$, Margarita A. Bureeva ${ }^{c}$, \\ Anastasia A. Efimova ${ }^{\mathrm{d}}$ \\ * Corresponding author: Elena G. Leontyeva, leoeg@mail.ru \\ ${ }^{a}$ National Research Tomsk Polytechnic University, Lenin Avenue, 30, Tomsk, Russia, leoeg@mail.ru, +79138250164 \\ ${ }^{b}$ Autonomous University of Barcelona, Bellaterra, Spain, Francesc.Romagosa@uab.cat, +34935929710 \\ ${ }^{c}$ National Research Tomsk Polytechnic University, Lenin Avenue, 30, Tomsk, Russia, msb6@tpu.ru, +79521642840 \\ ${ }^{d}$ National Research Tomsk Polytechnic University, Lenin Avenue, 30, Tomsk, Russia, staciataj@gmail.com, +79234157666
}

\begin{abstract}
http://dx.doi.org/10.15405/epsbs.2017.01.58

The absolute number of people all over the world aged 60 and older is expected to increase during the period from 2000 to 2050 from 605 million to 2 billion people. International organizations and institutions set as the task not only the increase in life expectancy but also active aging. In this paper, the authors try to prove that the development of sustainable tourism is one of the possibilities to help of prolonging the active life of the older generation. The paper analyses the sustainable tourism and successful aging concepts. The study concludes that the sustainable tourism is a way of improve the active life expectancy. The research concludes that tourist activity of the elderly is one of the main factors of the successful aging. Pursuit of activities is uncharacteristic for noninvolved in social activity elderly people. The paper analyses the several tourism products that are currently offered in Spain, in some cases specifically for the elderly, and under a sustainable tourism approach. Conducted analysis indicates that the level of subjective well-being of the elderly is increasing as the result of participation in sustainable tourism products.
\end{abstract}

C 2017 Published by Future Academy www.FutureAcademy.org.uk

Keywords: Sustainable tourism; successful aging; involvement of the elderly; involvement in social life; projects, elderly.

\section{Introduction}

Tourism had several stages of development from the Grand Tour in the 18th century to the concept of sustainable tourism, adopted in the last decade of the 20th century. While some countries have already felt the effects of mass tourism, receiving during the year millions of foreign tourists (France, USA, Spain, etc.) (UNWTO, 2016), other countries due to economic, social and political reasons, have not yet been able to offer expanded offer of touristic products (Brohman, 1996). One of the most active groups of tourists in the developed countries is middle-aged people (approximately $40 \%$ of all tourists are older than 55 years old). According to the World Health Organization (WHO, 2016) during the This is an Open Access article distributed under the terms of the Creative Commons Attribution-Noncommercial 4.0 Unported License, permitting all non-commercial use, distribution, and reproduction in any medium, provided the original work is properly cited. 
period from 2000 to 2050 , the proportion of the world's population over the age of 60 years old will double from about $11 \%$ to $22 \%$. The absolute number of people all over the world aged 60 and older is expected to increase over the same period from 605 million to 2 billion people. International organizations and institutions set as the task not only the increase in life expectancy but also active aging. In this paper, the authors try to prove that the development of sustainable tourism is one of the possibilities to help of prolonging the active life of the older generation.

\section{The goal}

The paper concerns the elderly subjective wellbeing and the successful aging conceptions. The elderly are sorted out into two categories for the study: the elderly involved in mass tourism and the elderly involved in sustainable tourism programs. The paper analyses projects in different countries in order to identify their impact on the level of subjective well-being for both categories of elderly people.

\section{The development of sustainable tourism concept}

27 September, 1970, the IUOTO Special General Assembly meeting in Mexico City adopted the Statutes of the World Tourism Organization (WTO). From 1980, this day is celebrated as «World Tourism Day». In 1992 WTO participated in the United Nations Conference on Environment and Development held in Rio de Janeiro (Brazil), where «Agenda 21» was created. Since that time tourism and sustainable development are connected and the concept of sustainable tourism has not stopped to grow and expand internationally (and increasingly accepted and developed by most part of the tourism sector and destinations). As examples of two key milestones for sustainable tourism, we can mention that in 2008 UNWTO and other UN agencies presented the Global Sustainable Tourism Criteria at the World Conservation Congress, Barcelona (Spain). Finally, the year 2017 has been declared by the UN International Year of Sustainable Tourism for Development.

According to the latest UNWTO data, international tourism grew by $4.4 \%$ in 2015 and reached 1,184 million. Over 50 million tourists more travelled abroad around the world during last year as compared to 2014 when over one billion international tourists travelled the world, supporting jobs, generating income and boosting development (UNWTO, 2016). International tourism currently accounts for 10\% of global GDP, 30\% of services exports and 1 in every 11 jobs (UNWTO, 2015).

Sustainable tourism programs are becoming more relevant considering the statistics, as each 7 th inhabitant of the planet became a tourist. But, what does the concept of «sustainable tourism» mean? WTO gives the following definition:

"Tourism that takes full account of its current and future economic, social and environmental impacts, addressing the needs of visitors, the industry, the environment and host communities".

Management practices of sustainable tourism and its development refer to all forms of tourism, including mass tourism and various tourism segments. Sustainability principles are applicable to the economic, environmental, and socio-cultural aspects of tourism development. In these three fields, a suitable balance must be established to guarantee its long-term sustainability (UNEP \& WTO, 2005).

Sustainable tourism should: 
1) Use optimally environmental resources that are the main element in tourism development, considering ecological processes and helping to conserve biodiversity and natural heritage.

2) Respect the socio-cultural norms of host places, conserving their traditional values and cultural heritage, and contribute to tolerance and inter-cultural understanding.

3) Ensure healthy, long-term economic operations, providing socio-economic benefits to all stakeholders, including stable employment and social services to host communities, and contribute to poverty alleviation.

Sustainable tourism should include two factors: on the one hand, strong political leadership to create condition for productive participation and consensus, on the other hand active participation of all relevant stakeholders. The process of maintenance of sustainable tourism is a continuous process. This process requires constant monitoring of impacts, in order to present the necessary preventive and/or corrective measures when necessary.

Sustainable tourism deals also with tourists. It provides a high level of tourist satisfaction and ensure a meaningful experience to the tourists, raising their awareness about sustainability issues and promoting sustainable tourism practices amongst them (UNEP \& WTO, 2005).

Sustainable tourism has the key principle the respect to the culture, traditions and socio-economic system of the people who live at the destination area. The main goal of sustainable tourism is to provide a positive impact on the environment, society and economy when visiting a place as a tourist.

Sustainable tourism is not a different or special form of tourism. It is important to understand that all forms of tourism should become more sustainable. Creating more sustainable tourism does not mean just controlling and managing the negative impacts of the industry. Rather, tourism is in a very special position to benefit local communities by economical and social impact, to raise awareness and support conservation of the environment (Aas et al, 2005). Within the tourism sector, environmental protection and economic development should be seen as joint forces-they should be pursued together as impulses to inspire that can and should be mutually reinforcing. Policies and actions must strength the benefits and reduce the costs of tourism. Many different interests can benefit from tourism being made more sustainable:

- Tourism enterprises should be concerned about the relationship with their staff, their corporate image, and their impact on the global environment, while seeking long term profitability.

- Local communities can increase prosperity but without damage to their quality of life.

- Environmentalists will be satisfied by reducing of harmful impacts of tourism and by seeing it as a valuable source of income for conservation.

- Tourists will have a high quality experience in safe and attractive environments; they will become more aware of the impacts of their travelling.

Sustainability is the responsibility of all those involved in tourism. In seeking more sustainable tourism, governments must recognize the different positions. The majority of the impacts of tourism are the result of actions taken by private sector enterprises and by tourists themselves (Priestley \& Romagosa, 2013). 


\section{Factors affecting the level of subjective well-being}

Considering the fact that Healthy Ageing starts with our genetic inheritance, only $25 \%$ of the diversity in longevity is explained by genetic factors. The other $75 \%$ is the result of the cumulative impact of our interactions with our physical and social environments, which shape behaviors and exposures across the life course (WHO, 2015). How important is tourism in the lives of older people? Consider the experience of the Spanish Government in this matter through the IMSERSO service (IMSERSO, 2016). Under the auspices of the Spanish Government there was created a state structure already in the 1980 s, called «Institute for older people and social services», which is integrated within the Ministry of Health, social services and equality (Fig.1).

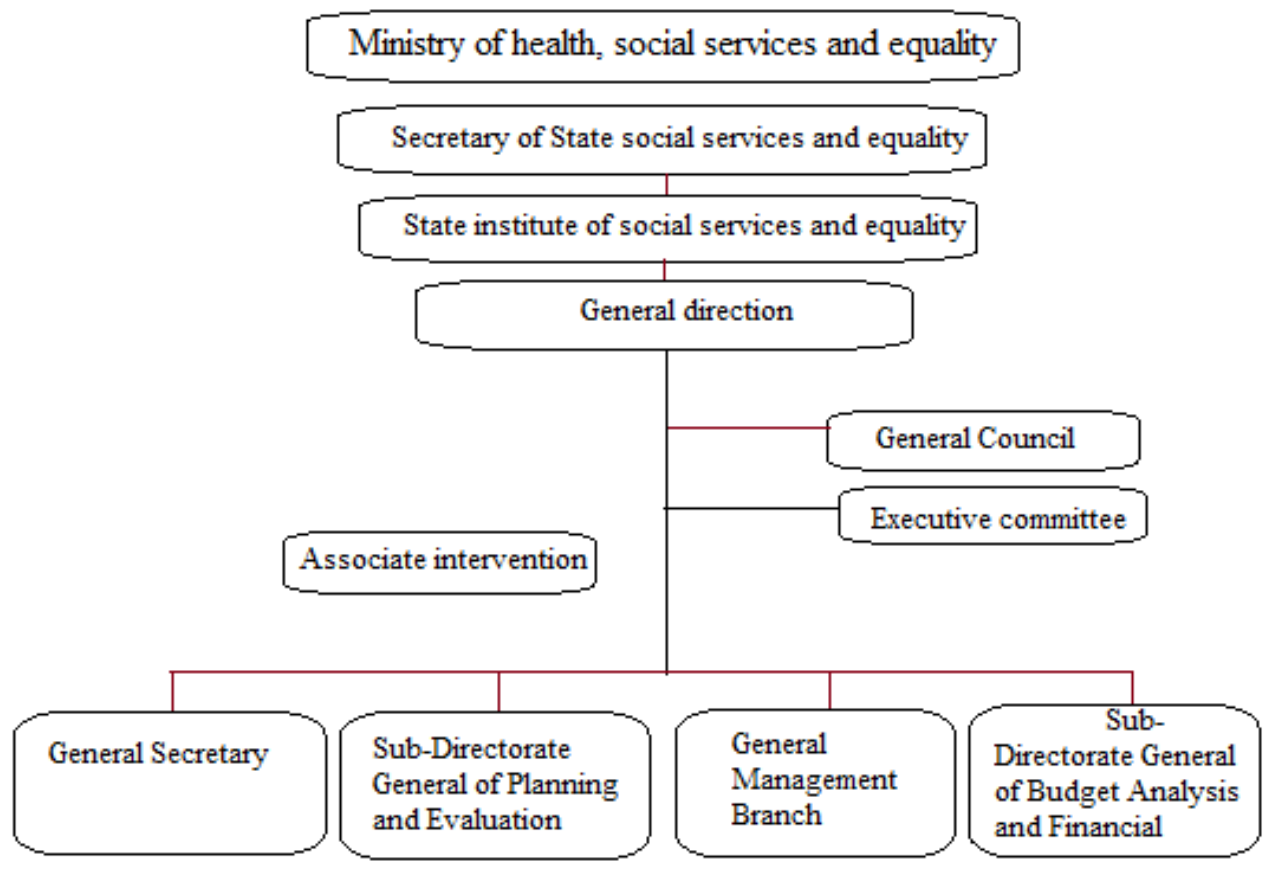

Fig. 1. Ministry of health, social services and equality.

This service offers a program for active aging, which includes:

1. Tourism Program.

2. Treatment program at thermal springs.

3. Active aging and solidarity between generations in Europe.

4. White Paper on «Active Aging».

The tourism program (falling under the so-called «social tourism») is aimed, on the one hand, to facilitate the inclusion of older people in the tourist industry, on the other hand to soften the effects of the seasonality of the tourism market. Various tourist programs are offered from October to June: seaside, visits to cultural and natural sightseeing. The tourist package includes round-trip travel, accommodation in 2-bed room (for single room additional fee), full board, insurance, medical care. The cost of a tourist package is $166.03 € 8$ days ( 7 nights) on the mainland and $314.23 €$ for a ticket to the Balearic or Canary Islands. 
The treatment program offers treatment in the health tourism resorts of Spain, including the initial examination of the doctor, treatment in accordance with the doctor appointments and medical support throughout stay, as well as accommodation in a double room and medical insurance.

The program of active aging and solidarity between generations in Europe involves various joint cultural and recreational routes of older people with their children and grandchildren. In Spain, there are developed thousands of tourist routes of different levels of difficulty with the cultural, architectural and historical sightseeing .

The White Paper on «Active Aging» is the document, developed by the Government of Spain, which is aimed at the implementation of policies aimed at improving the lives of older people. The document includes more than one hundred proposals that meet the desires and expectations of older people related to their future (Page \& Connell, 2008).

The results of the active aging program is the fact that $53 \%$ of older people have started a new activity after 65 years. In 1993 only 9.5\% of people age 65 began a new activity. 43\% of middle aged people are actively involved in the public life of the Spanish society. $28 \%$ participate in some public organizations and $8 \%$ work voluntarily. $87 \%$ want to live in their homes and to support family relationships. Due to the «intergenerational» program $70 \%$ look after their grandchildren. Physical training activities are also a priority in the activities for older people. $86 \%$ were not enrolled in primary school, because they were children at the time of the Civil War and Second World War, but in 2007, $8 \%$ expressed the desire to learn. $45.5 \%$ say about the good health, this figure was $37 \%$ in 1993 , at the same time, the percentage of older people who is complaining of poor health, decreased from $24 \%$ to $14.5 \%$. All these figures, according to IMSERSO (2016), show that policies aimed at the health and social well-being of older people, has a direct effect on improving the quality of life.

As it can be seen from the above experience the concept of «sustainable tourism» did not appear in the documents of the Spanish government. How can we associate the concept of «sustainable tourism» and successful aging will be discussed in the following section.

\section{Sustainable tourism in elderly social life}

Sustainable tourism products and initiatives have been developed in Spain during the last 20 years, including the development of nature tourism products, linked to protected areas, and cultural tourism products (both in the cities and in the rural areas).

Spain is the country with the largest number of Biosphere Reserves (a total of 45 as appointed by UNESCO). Spain has more than 30 protected natural areas that are certified under the European Charter for Sustainable Tourism (CST). Tourist companies offer activities in these natural areas remaining committed to protecting the environment. Visiting these natural environments enables visitors to combine leisure with the preservation of ecological and landscaping values. The Garajonay National Park, on the Canary Island of La Gomera, and the Garrotxa National Park, in Catalonia, are examples of the implementation of the CST. Garajonay belongs to both the National Park network and the Biosphere Reserves (Blanco, 2009).

Also Spain belongs to the Ramsar Convention or the Convention concerning wetlands of international importance, which includes over 70 Spanish wetland areas. Spain tries to maintain the 
ecosystem and guarantee the future of aquatic birds. The wetlands in Doñana, in Andalusia, the Tablas de Daimiel, in Ciudad Real, and the Ebro delta, in Catalonia, are some of the most popular natural spaces visited by foreign tourists.

Some marine areas are protected areas as part of the Mediterranean Action Plan. Thus, the unique coastal and marine ecosystems are safeguarded (Marca España, 2015).

Spain participates in several international schemes to promote sustainable tourism. The example is the Sustainability and Tourism Forum, FITUR Green, in the FITUR Tourism Fair, celebrated annually in Madrid. The organisers of this event is Hotel Technology Institute, which promotes the efficiency and sustainability of companies linked to the hotel and tourism industry. The result of that work is that today Spanish tourism companies have a notably ecological and sustainable profile.

One of sustainable tourism projects, which is very popular not only among Spain, but also among foreign tourists, is the The Camino de Santiago (Latin: Peregrinatio Compostellana). Also known by the English names Way of St. James or Road to Santiago, is the name of any of the pilgrimage routes, known as pilgrim ways, to the shrine of the apostle St. James the Great in the Cathedral of Santiago de Compostela in Galicia (northwestern Spain), where tradition says that the remains of the saint are buried. Many people take up this route as a form of spiritual path or retreat for their spiritual growth (Mowforth \& Munt, 2008). A network of four Christian pilgrimage routes in northern Spain, are an extension of the Route of Santiago de Compostela, a site inscribed on the UNESCO's World Heritage List in 1993. The extension represents a network of almost 1,500 km: coastal, interior of the Basque Country-La Rioja, Liébana and primitive routes. It includes a built heritage of historical importance created to meet the needs of pilgrims, including cathedrals, churches, hospitals, hostels and even bridges. The extension encompasses some of the earliest pilgrimage routes to Santiago de Compostela, following the discovery in the 9 th century of a tomb believed to be that of St. James the Greater. The number of pilgrims has increased from 690 people in 1985 to 262,458 in 2015. Despite the complexity of the route pilgrims take $20-30 \mathrm{~km}$ during the day. There are different age groups, including a large number of people older 55 years. Participation in the route The Camino de Santiago helps people to keep fit, to get acquainted with the cultural and historical values of the region, to comprehend their problems and tasks at the current stage of life.

According the Spanish official statistics on tourism (Ministerio de Educación, Cultura y Deporte, 2015), in $201416.4 \%$ of domestic tourists that were older than 64 years had a cultural motivation for travelling within Spain, and those of them that travelled for cultural purposes spent an average of 537 euros per trip (while the average for all the group ages was 425 euros). Regarding international tourists older than 64 years that went to Spain in 2014 (10\% of the total), 55\% of them made one or more cultural activities while they stayed in the country as tourists, and they spent an average of 1,167 euros per trip (a higher number than the average for all the group ages of international tourists: 1,074 euros). These figures, although quite general, show the growing importance of the older adults tourists in the cultural tourism in Spain, as well as its potential connection with all the previously mentioned sustainability initiatives, as most of them have a clear link with cultural tourism. 


\section{Conclusion}

The study shows: the older generation cannot be described only in terms of disease and poverty. For many people, the old age is a time of self-realization, interesting leisure-time, new relationships with people and emotional experiences. Today as the world average life expectancy is increasing, the projects to include this group in the active life are particularly relevant. The program for sustainable tourism may be one of them. The participation of older people in such programs can solve a number of tasks aimed to improve the quality of life of this group of the population:

1. Education: older people understanding of the negative impact of mass tourism on the environment, which manifests itself in the noise and air pollution from increasing traffic, in the contamination of water sources and in the loss of natural habitats. Solving of educational tasks helps to form new thinking of older people with a focus on sustainable development and the acquisition of new environmentally and socially friendly tourist experience.

2. Teaching: older people not only become the actors of sustainable tourism programs but also they become active propagandists of this trend among younger generation, in their families, for children and grandchildren.

3. Physical training: implementation of a sustainable tourism programs for older people in rural areas, in small rural hotels close to nature helps to keep fit constantly by taking long walks, biking, swimming, hiking, etc. They become active in comparison with traditional mass tourism programs.

4. Wellness: fresh air, quality food due to fresh food from nearby farms, lack of noise and pollution considerably improve the state of health of older people.

5. Culture: discover of the cultural and historical values and traditions of the region allows to expand the horizons and to develop the aesthetic tastes of older people.

Thus, participating in sustainable tourism programs, the older people not only improve their educational, physical and cultural level, but also become active participants in promoting sustainable development and building a «more secure, equitable, green, and prosperous world for all» (UNWTO, 1999). Active life position of older people, which is formed due to the participation in these programs, helps to increase the length of active life.

\section{References}

(UNWTO) World Tourism Organization (2015). Affiliate Members Global Reports. Volume eleven - PublicPrivate Partnerships: Tourism Development, UNWTO, Madrid. (UNWTO) World Tourism Organization. Tourism Highlights. (2016). Retrieved from http://mkt.unwto.org/publication/unwto-tourism-highlights-2016-edition

(WHO) World Organization of Health. Draft global strategy and plan of action on ageing and health (2015,

March10). Retrieved from http://www.who.int/ageing/global-strategy/en/

(WTO) World Tourism Organization(1999). Global Code of Ethics for Tourism. Retrieved from http://ethics.unwto.org/en/content/global-code-ethics-tourism

Aas, C., Ladkin, A., Fletcher, J. (2005). Stakeholder collaboration and heritage management. Annals of Tourism Research, 32 (1), 28-48.

Blanco, R. (2009). Ecotourism in Spain. Madrid: Tourspain, 34-40.

Brohman, J. (1996). New Directions in Tourism for Third World Development. Annals of Tourism Research, 23 (1), 48-53. 
eISSN: $2357-1330$

Selection \& Peer-review under responsibility of the Conference Organization Committee

IMSERSO, Instituto de Mayores y Servicios Sociales (2016). Retrieved from

http://www.imserso.es/imserso_01/index.htm

Marca España (2015). Sustainable tourism. Retrieved from http://marcaespana.es/en/culture-and-

singularity/tourism/sustainable-tourism

Ministerio de Educación, Cultura y Deporte (2015). Anuario de estadísticas culturales 2015. Madrid.

Mowforth M., Munt I. (2008). Tourism and Sustainability: New Tourism in the Third World. London: Routledge.

Page S., Connell J. (2008). Sustainable tourism: 4 Volume Collection. London: Routledge.

Priestley G., Romagosa F. (2013). Introduction: innovation, technology, knowledge and new horizons in tourism management. Priestey G., Romagosa, F. (eds.) New horizons in tourism. Autonomous University of Barcelona, $17-25$

UNEP, WTO (2005). Making Tourism More Sustainable. A Guide for Policy Makers. United Nations Environment Programme \& World Tourism Organization, Madrid. 